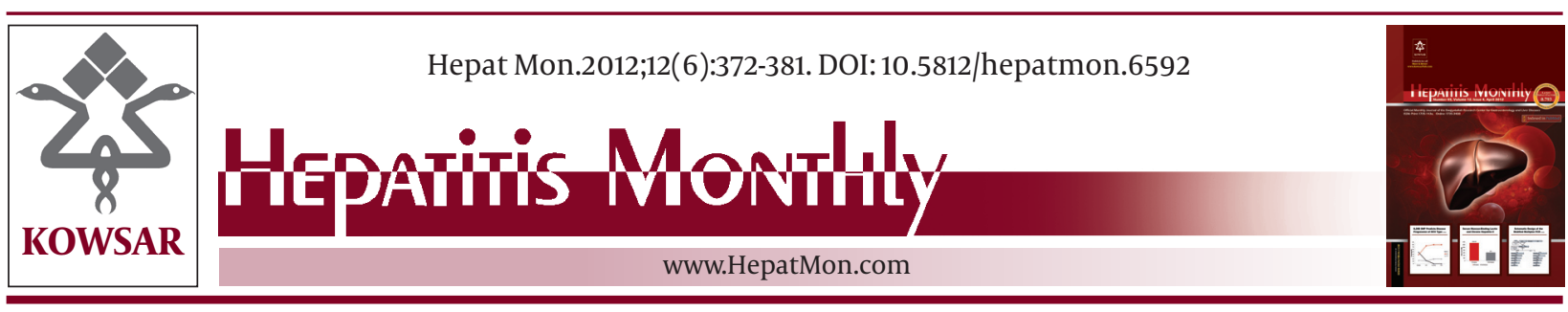

\title{
Low Dose Ribavirin for Treatment of Hepatitis C Virus Infected Thalassemia Major Patients; New Indications for Combination Therapy
}

\author{
Seyed Vahid Tabatabaei ${ }^{1}$, Seyed Moayed Alavian ${ }^{1{ }^{*}}$, Maryam Keshvari ${ }^{2}$, Bita Behnava ${ }^{1}$, Seyyed \\ Mohammad Miri ${ }^{1}$, Pegah Karimi Elizee ${ }^{2}$, Farhad Zamani ${ }^{3}$, Sedigheh Amini Kafiabad ${ }^{2}$, Ah- \\ mad Gharehbaghian ${ }^{2}$, Bashir Hajibeigy ${ }^{2}$, Kamran Bagheri Lankarani ${ }^{4}$
}

${ }^{1}$ Baqiyatallah Research Center for Gastroenterology and Liver Disease, Baqiyatallah University of Medical Sciences, Tehran, IR Iran

2 Iranian Blood Transfusion Organization Research Centre (IBTO), Tehran, IR Iran

3 Liver Disease Research Center, Iran University of Medical Sciences, Tehran, IR Iran

4 Shiraz University of Medical Sciences, Shiraz, IR Iran

\begin{tabular}{l}
\hline A R T I C L E I N F O \\
\hline Article type: \\
Original Article \\
\hline Article history: \\
Received:10 May 2012 \\
Revised:15 May 2012 \\
Accepted: 30 May 2012 \\
\hline
\end{tabular}

Keywords:

Beta-Thalassemia

Hepacivirus

Ribavirin

Peginterferon Alfa-2a

\begin{abstract}
A B S T R A C T
Background: Treatment guidelines contraindicate ribavirin for treatment of hepatitis $C$ virus (HCV) infection in thalassemia major patients. Nevertheless, the current evidence suggests that ribavirin might be tolerated by these patients.

Objectives: Despite this evidence, low dose ribavirin combination therapy has not been compared with peginterferon monotherapy in these patients so far.

Patients and Methods: Two hundred eighty thalassemia patients with detectable HCVRNA PCR $(\geq 50 \mathrm{IU} / \mathrm{mL})$ and liver histology consistent with chronic HCV infection were selfassigned to receive peginterferon alfa-2a $(n=81)$ monotherapy or its combination therapy with ribavirin, 600-800 mg QD, according to hemoglobin levels $(n=199)$. Treatment experienced patients were eligible for this study.

Results: Sustained virological response (SVR) was significantly higher in patients who received ribavirin ( $51 \%$ vs. $38 \% P=0.02)$. In multivariate regression, OR of ribavirin for prediction of SVR was 2.2 (95\% CI 1.24-3.91). The SVR was significantly higher in the ribavirin group in subgroups of patients with more than 24 years of age, elevated ALT, ferritin < $2006 \mathrm{ng} /$ $\mathrm{mL}$, previous treatment failure, genotype 1 , positive history of splenectomy, fibrosis score of 0-4 HAI and viral load $<600,000 \mathrm{IU} / \mathrm{mL}$. Treatment discontinuations due to the safety concerns were comparable between the treatment groups (6.5 and $8 \%$ ). Furthermore, transfusion intervals were almost halved in patients who received low dose ribavirin.

Conclusions: According to the present study, adult thalassemia patients with HCV infection can be treated successfully with low dose ribavirin. Hence, we strongly advise combination therapy in thalassemia patients with aforementioned clinical characteristics. Moreover, ribavirin does not seem to be beneficial in thalassemia patients below 18 years of age.

Copyright $\odot 2012$ Kowsar Corp. All rights reserved.
\end{abstract}

- Implication for health policy/practice/research/medical education:

New treatment methods in special patients with thalassemia could be a challenge among clinicians especially internists. This topic is not discussed in other studies and originated form a national trial.

\section{- Please cite this paper as:}

Tabatabaei SV, Alavian SM, Keshvari M, Behnava B, Miri SM, Karimi Elizee P, et al. Low Dose Ribavirin for Treatment of Hepatitis C Virus Infected Thalassemia Major Patients; New Indications for Combination Therapy. Hepat Mon. 2012;12(6):372-81. DOI:10.5812/hepatmon.6592

* Corresponding author: Seyed-Moayed Alavian, Baqiyatallah Research Center for Gastroenterology and Liver Disease, Baqiyatallah Hospital, Mollasadra Ave., Vanak Sq. P.O. Box: 14155-3651, Tehran, IR Iran. Tel: +98-2188067114, Fax:+98-2188067114. E-mail: editor@hepatmon.com

DOI:10.5812/hepatmon.6592

Copyright $\odot 2012$ Kowsar Corp. All rights reserved. 


\section{Background}

Chronic hepatitis C (CHC) is a major cause of morbidity and mortality in thalassemia major patients, particularly in those who received their first transfusion before the introduction of HCV donor screening program (1). Since sustained virological response (SVR) to anti-HCV therapy avoids fibrosis progression, decreases the risk of HCC, and improves patients' survival, it is a crucial option in management of these patients (2-5). In patients without hemoglobinopathies, current guidelines strongly recommend combination therapy of ribavirin and either peginterferon alfa-2a or $2 \mathrm{~b}$. This combination therapy can yield a SVR rate of more than 50 \% in genotype 1 and $70-80 \%$ of SVR in genotype $2 / 3$ infected patients (6-10). In contrast to patients without inherent hemoglobinopathy, ribavirin, that is one of the major determinants of the SVR, can induce life-threatening anemia in thalassemia major patients, and thus, is generally considered contraindicated in these patients $(11,12)$. In addition to contraindication of ribavirin, high iron content of serum and liver with its probable role in conferring patients' interferon resistance and its synergistic effect on progression of liver fibrosis is another major confounder in treatment of thalassemia major patients (13-19). Previously in a meta-analysis of literature, we showed that peginterferon monotherapy can induce a SVR rate of 28 percent in thalassemia major patients, while combination therapy of peginterferon and ribavirin (low dose therapy, accompanying by tight monitoring of patients) elicits a SVR rate of 44 percent (20). The small sample size and lack of control group in included studies were two major downsides of our meta-analysis (21-26). Indeed, this study has been designed to address this issue and to reach a more precise estimation of ribavirin tolerability and the effect of its low dose administration on improving SVR in HCV infected thalassemia major patients.

\section{Objectives}

In current study peginterferon alfa-2a plus low dose ribavirin combination therapy has been compared with peginterferon alfa-2a monotherapy in a head to head open-labeled clinical trial of 280 patients. This huge number of patients could let us determine major subgroups that benefit the most from low dose ribavirin.

\section{Patients and Methods}

\subsection{Patient Selection}

280 thalassemia major patients with quantifiable serum HCV RNA levels (> $50 \mathrm{IU} / \mathrm{mL}$ ) and liver biopsy findings consistent with diagnosis of chronic HCV infection were enrolled in our study. Our exclusion criteria were as follows: 1) hepatitis B virus or HIV co-infection, 2) decompensated liver disease, 3) hepatocellular carcinoma, 4) bone marrow or liver transplant, 5) creatinine clearance
$<50 \mathrm{~mL} / \mathrm{min}, 6$ ) poorly controlled psychiatric disorder, 7) poorly controlled diabetes, 8) malignant neoplastic disease, 9) severe cardiac or chronic pulmonary disease, 10) active substance abuse, 11) immunologically mediated disease, or 12) retinopathy. Patients with previous treatment failure following conventional interferon with or without ribavirin therapy were still eligible.

\subsection{Study Design}

This study was designed as a single centre, prospective open-label controlled trial of peginterferon alfa-2a (Pegasys $®$ ) and ribavirin (COPEGUS $®$ ) combination therapy in HCV infected thalassemia major patients. Sponsors of this study and the academic principal investigators were jointly responsible for the study design and its protocol development. This study has been conducted at Iranian blood transfusion organization hepatitis clinic, and has been registered in www.clinicaltrials.gov (identifier: NCT00707850). Eligible subjects were self-assigned to two treatment groups. Patients in the group (A) received $180 \mu \mathrm{g}$ of Pegasys® subcutaneously once a week in combination with oral ribavirin $600-800 \mathrm{mg}$ per day according to patients' hemoglobin level. Patients with a hemoglobin level of 8-10 g/dL received $600 \mathrm{mg}$ ribavirin, whereas those with hemoglobin level of over $10 \mathrm{~g} /$ dL received $800 \mathrm{mg}$ Rbavirin. Genotype 1 and mixed infection were treated for a total duration of 48 weeks, while patients with genotype 2 or 3 were treated for 24

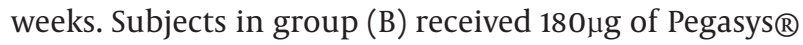
subcutaneously once a week for duration of 48 weeks. As ribavirin is not approved for administration to patients with hemoglobinopathies, randomization and blinding of patients to treatment regimens were recognized unethical and were avoided. Therefore, all patients underwent consultation regarding the potential benefits and hazards of ribavirin in aggravation of their underlying disease and its likely significant effects on their anti-HCV treatment outcome. Consequently, 199 subjects accepted to receive ribavirin and were assigned to group (A) and 81 subjects that declined were assigned to group (B). Meanwhile, thalassemia major had been confirmed in all patients with hemoglobin electrophoresis or DNA testing earlier in their life. In addition, all subjects had been receiving regular blood transfusions at two to four week intervals along with regular therapy with defroxamine to maintain hemoglobin levels at 10-13 g/dL. Compliance with treatment was monitored using telephone consultation, questionnaires and returned vials for peginterferon alfa2a. The protocol was approved by the ministry of health appointed Protocol Review Committee as well as the Iranian Blood Transfusion Organization and Baqiyatallah University of Medical Sciences Review Boards. All patients provided written informed consent. Informed consent was also obtained from parents of patients younger than the legal age ( $<18$ years). 


\subsection{Liver Histology}

Patients underwent percutaneous liver biopsy by Menghini needles. Each biopsy specimen was evaluated according to the modified Knodell score grading and staging system by a single pathologist who was blind to patients' clinical and laboratory data and treatment regimens. The Perls' staining method with 0-4 score was applied to assess hepatic siderosis. 50 subjects with liver biopsy results of older than two years ago declined to perform a new liver biopsy. Thus, their data of liver histology were considered missing in the statistical analysis.

\subsection{Assessment of Efficacy}

Our primary efficacy end point was the sustained virological response, defined as undetectable HCV RNA after 24 weeks of untreated follow-up. Our secondary efficacy end points were early virological response (EVR) defined as negative HCV-RNA after 12 weeks of treatment and end of treatment response (ETR) which is negative HCV RNA at the end of treatment. According to the established guidelines, patients with an insufficient virological response at 12th week (a detectable HCV RNA level and a decrease of $<2 \log _{10} \mathrm{IU} / \mathrm{mL}$ from the baseline level) and a detectable HCV RNA level at 24th week of treatment were considered to show treatment failure and were withdrawn from treatment. Analysis included data from all patients who received at least one dose of studied medications.

\subsection{Assessment of Safety}

Safety was assessed by monthly laboratory tests and evaluation of adverse events during treatment and follow-up period in group (B). On the other hand, patients' hemoglobin level was checked every week in group (A), until the recognition of transfusion necessity and afterward, according to the pattern of identified hemoglobin drop. Adverse events were graded by the investigators as mild, moderate, severe, or life-threatening, according to a modified world health organization (WHO) grading system. Non-life-threatening adverse events were managed by reduction of the dose of peginterferon alfa-2a, or with appropriate medical treatments. The laboratory criteria for dose reduction of peginterferon alfa-2a or treatment discontinuation were as follows: 500-750 neutrophils/ $\mathrm{mm} 3$ and 30000-50000 platelets / $\mathrm{mm} 3$ for dose reduction and decline of neutrophil count to below 500/mm3 and platelet count to below $30000 / \mathrm{mm} 3$ for treatment discontinuation. Furthermore, the interval between transfusions was reduced if it was necessary to maintain the hemoglobin level between 10 and $13 \mathrm{~g} / \mathrm{dL}$. Whenever the patients developed an abnormal laboratory test, they were asked to return and to be retested at an interval of one or two weeks, in addition to dose adjustment or temporary treatment discontinuation. Afterwards, further modifications were introduced to treatment regimen or treatment was even discontinued according to the pa- tients' condition.

\subsection{Virological Methods}

HCV genotyping was carried out according to the method that has been described previously (27). Viral load quantification was performed using the Cobas Amplicor HCV Monitor, v2.0 (Roche Diagnostics, Branchburg, NJ, USA) with a lowest detection level of 50 IU/mL HCV RNA.

\subsection{Statistical Analysis}

The current trial was designed to detect clinically meaningful differences of the rates of SVR and patients' safety between two treatment regimens in general and in subset of patients. Statistics are summarized in tables for each of the two treatment regimens. Continuous variables are presented as mean values \pm standard deviation (SD), while qualitative and discrete variables are presented as absolute and relative frequencies in the form of percentage. Chi-squared test was applied to assess associations between categorical variables. The comparisons between continuous and qualitative variables were performed by student's t-test. Multivariable logistic-regression analyses involving treatment regimen, baseline characteristics and previous treatment history were performed to study SVR in all studied populations. A stepwise procedure was used to identify independent predictors of SVR with $P=$ 0.05 as the threshold level for variables to be entered into and retained in the final model, and $P=0.1$ as the threshold level for variables to be removed. All computations were carried out using SPSS version 16.

\section{Results}

\subsection{Characteristics of Studied Patients}

Totally, 280 patients were included in the present study, with their age ranging from 11 to 54 years (mean: $24.2 \pm$ 0.3 years). From them, $60 \%$ were male. The mean body weight of patients was $51.5 \pm 0.6 \mathrm{~kg}$ (ranging between 23 and $81 \mathrm{~kg}$ ). Average of serum ALT values was 2.2 times the upper limit of the normal range. Mean baseline viral load was $774,000 \mathrm{IU} / \mathrm{mL}$ and $24 \%$ had an HCV RNA level of $>1$ million IU/mL. $71 \%$ were infected with genotype 1 . Liver necro inflammation was mild in 135 patients (59\%), while it was moderate and severe in $81(35 \%)$ and $9(4 \%)$ patients respectively. From the other side, liver fibrosis was mild in $66(29 \%)$, moderate in $62(30 \%)$ and bridging in 81 (35 $\%)$ patients, whereas 21 patients ( $9 \%$ ) had cirrhosis. Baseline demographic characteristics were balanced between the two treatment groups (Table 1). However, patients in group (A) who received ribavirin had a significantly higher rate of previous treatment failure, serum ferritin and liver enzymes.

\subsection{Virologic Response Rates and Treatment Efficacy}

Treatment was administered through 24 or 48 weeks according to the HCV type and treatment regimen. Figure 


\begin{tabular}{|c|c|c|c|}
\hline & Group A & Group B & Pvalue \\
\hline Patients, No. & 199 & 81 & \\
\hline Gender & & & 0.1 \\
\hline Male, No. & 123 & 42 & \\
\hline Female, No. & 76 & 39 & \\
\hline Mean, \% & 62 & 60 & \\
\hline Mean Age, Mean \pm SD & $24 \pm 5.5$ & $25 \pm 7.2$ & 0.3 \\
\hline range & $11-43$ & $12-54$ & \\
\hline $\mathrm{BMI}^{\mathrm{c}}$, Mean $\pm \mathrm{SD}$ & $20.4 \pm 0.2$ & $20.2 \pm 0.2$ & \\
\hline range & $14-28$ & $15-25$ & \\
\hline $\operatorname{ALT}^{\mathrm{c}}(\mathrm{U} / \mathrm{L})$, Mean $\pm \mathrm{SD}$ & $91 \pm 56$ & $79 \pm 60$ & 0.06 \\
\hline range & $12-994$ & $15-338$ & \\
\hline $\operatorname{Normal}(<40 \mathrm{U} / \mathrm{L})$, No. $(\%)$ & $35(18)$ & $24(30)$ & 0.02 \\
\hline Elevated, No. (\%) & $164(82)$ & $57(70)$ & 0.02 \\
\hline $\operatorname{AST}^{\mathrm{c}}(\mathrm{U} / \mathrm{L})$, Mean $\pm \mathrm{SD}$ & $77 \pm 61$ & $64 \pm 41$ & 0.08 \\
\hline range & $17-638$ & $13-206$ & \\
\hline Normal (<40 U/L), No.(\%) & $43(22)$ & $29(36)$ & 0.01 \\
\hline Elevated, No. (\%) & $156(78)$ & $62(64)$ & 0.01 \\
\hline $\mathrm{Hb}^{\mathrm{c}}$, Mean $\pm \mathrm{SD}$ & $10 \pm 1.5$ & $9.5 \pm 1.3$ & 0.4 \\
\hline $\mathrm{HCV}^{\mathrm{c}}$ viral load $^{\mathrm{d}}(\mathrm{IU} / \mathrm{mL})$, Mean $\pm \mathrm{SD}$ & $800000 \pm 11000$ & $799000 \pm 88000$ & \\
\hline range & $2000-8000000$ & $7540-4090000$ & \\
\hline $\log _{10}$ Serum HCVViral Load $(\mathrm{IU} / \mathrm{mL})$, Mean \pm SD & $5.5 \pm 0.7$ & $5.5 \pm 0.6$ & 0.5 \\
\hline$>6$ (copy/ml), No. $(\%)$ & $85(43)$ & $31(38)$ & \\
\hline Serum ferritin $(\mathrm{ng} / \mathrm{mL})$, Mean \pm SD & $2130 \pm 1777$ & $1710 \pm 1498$ & 0.06 \\
\hline range & $210-8132$ & $300-6650$ & \\
\hline \multicolumn{4}{|l|}{ History of Splenectomy, y, No.(\%) } \\
\hline Yes/No & $135 / 64(68)$ & $49 / 32(60)$ & 0.2 \\
\hline \multicolumn{4}{|l|}{ HCVType } \\
\hline Genotype 1, No.(\%) & $119(60)$ & $41(51)$ & 0.1 \\
\hline Genotype 2, No.(\%) & $1(0.5)$ & $2(2.5)$ & 0.1 \\
\hline Genotype 3, No.(\%) & $65(33)$ & $33(41)$ & 0.1 \\
\hline Mixed infection, No.(\%) & $10(5)$ & $2(2.5)$ & 0.1 \\
\hline Untypable, No.(\%) & $4(2)$ & $3(4)$ & 0.1 \\
\hline Stage of liver fibrosis, Mean \pm SD & $3.2 \pm 1.6$ & $3.3 \pm 1.4$ & 0.5 \\
\hline $0-2$, No. $(\%)$ & $50(31)$ & $16(20)$ & 0.3 \\
\hline 3-4, No. (\%) & $69(43)$ & $37(53)$ & 0.3 \\
\hline $5-6$, No. $(\%)$ & $41(26)$ & $17(24)$ & 0.3 \\
\hline Grade of liver inflammation, Mean \pm SD & $6.3 \pm 0.2$ & $6.3 \pm 0.4$ & 0.9 \\
\hline $0-6$, No. (\%) & $92(59)$ & $43(63)$ & 0.7 \\
\hline 7-12, No. (\%) & $58(37)$ & $23(34)$ & 0.7 \\
\hline 13-18, No. (\%) & $7(4.5)$ & $2(3)$ & 0.7 \\
\hline Stage of liver sidrosis, Mean \pm SD & $3 \pm 1$ & $2.9 \pm 1$ & \\
\hline $0-2$ & $37(19)$ & $16(20)$ & 0.2 \\
\hline $3-4$ & $118(59)$ & $34(42)$ & 0.2 \\
\hline Previous treatment & $136(68)$ & $38(47)$ & 0.001 \\
\hline Naïve & $61(31)$ & $43(53)$ & 0.0006 \\
\hline Standard IFN ${ }^{\mathrm{c}}$ & $62(31)$ & $24(30)$ & 0.8 \\
\hline Standard IFN + RVB ${ }^{\mathrm{c}}$ & $74(37)$ & $14(17)$ & 0.001 \\
\hline
\end{tabular}

${ }^{a}$ Except for liver enzymes and serum ferritin there were no significant differences among the two treatment groups with regard to baseline characteristics.

${ }^{b}$ Percutaneous liver-biopsy specimens obtained before treatment were evaluated according to modified knodell score scaling system. The modified knodell scoring system classifies fibrosis according to a 6-point scale: 0, no fibrosis; 1 , Fibrous expansion of some portal areas; 2, Fibrous expansion of most portal areas; 3, Fibrous expansion of most portal areas with occasional portal to portal bridging; 4, Fibrous expansion of portal areas with marked bridging of portal to portal as well as portal to central; 5, Marked bridging with occasional nodules; 6, Cirrhosis.

c Abbreviations: ALT, denotes alanine aminotransferase; AST, aspartat aminotransferase; BMI, body mass index; Hb, hemoglobin; HCV, hepatitis C virus; IFN, interferon; RVB, ribavirin

${ }^{d}$ Hepatitis C virus level was determined with the use of the amplicor assay version II (Roche), for which the lower limit of quantitation is 50 IU per milliliter. 
1 shows the virological response which is defined as an undetectable serum hepatitis $\mathrm{C}$ virus (HCV) RNA level (< $50 \mathrm{IU} / \mathrm{mL}$ ) during the study period in 199 patients with combination therapy and 81 patients who received monotherapy. Patients with missing HCV RNA measurements at the various time points were considered as not having a response. The primary end point of SVR was measured at 24 weeks after treatment cessation. The percentage of patients with SVR was $51 \%$ (95\% CI, 44 to 58) for group (A) and $38 \%$ (95\% CI, 27 to 48) for group (B). The estimated difference in SVR rates was 13 \% (95\% CI 2-23). Response rates at the end of the treatment phase did not differ between groups (A) and (B). However, virological relapse rate was significantly higher in patients who received peginterferon alfa-2a monotherapy (35\%vs. $23 \%$ ). Our primary analysis in a multiple logistic model controlled for all baseline characteristics revealed that the rate of SVR was significantly higher in patients who were given low dose ribavirin therapy [OR $=2.295 \% \mathrm{CI}$ 1.24-3.91]. In both groups, HCV RNA suppression (negative HCV RNA with qualitative PCR at treatment week 12) was strongly associated with a sustained virological response $(P<0.0001)$ and was also significantly higher in the group (A) (Figure 1). Stepwise multivariable logistic-regression analyses identified several baseline factors such as being treated with ribavirin, female gender, age $<24$ years and HCV type as independent predictors of sustained virological response (Figure 2). The odds ratios of the SVR among patients who received combination therapy to patients who received monotherapy according to baseline characteristics are shown in Figure 3. A far more pronounced effect of low dose ribavirin was observed in patients with one of the following baseline characteristics: age $\geq 24$, elevated ALT level, history of splenectomy, HCV genotype 1, viral load $<600,000 \mathrm{IU} / \mathrm{mL}$, serum ferritin $<2006 \mathrm{ng} / \mathrm{mL}$, liver modified-HAI fibrosis of 0 to 4 and previous treatment failure.

\subsection{Drug Doses and Side Effects}

Follow up of patients from enrollment to 24 weeks after treatment cessation is shown in Figure 4. The peginterferon alfa-2a dose was reduced in $19 \%$ of group (A) and $18 \%$ of group (B) patients. Besides, the ribavirin dose fluctuated in group (A) patients according to their hemoglobin level. Compliance with treatment was similar in both groups, so were discontinuation rates (24\% in group (A) and $26 \%$ in group (B). Adverse events were reported in $85 \%$ of all studied patients [ $86 \%$ in group (A) and 83 $\%$ in group (B)], and most of the events were considered to be related to treatment. Table 2 shows adverse events and laboratory abnormalities in detail according to the treatment regimen. The incidence was similar in both treatment groups. Four patients died because of sepsis, two patients died of diabetic ketoacidosis and two deaths occurred in patients with heart failure. It should be mentioned that diabetic ketoacidosis was attributed to lack of compliance with insulin use in both subjects. Discontinuation of treatment due to adverse events occurred in $4 \%$ of both treatment arms (Figure 4). In patients who received combination therapy, transfusion intervals were almost halved to maintain hemoglobin above $10 \mathrm{~g} / \mathrm{dL}$. Consequently, hemoglobin level was remained constant during combination therapy (Figure 5). Regarding transfusion rate during therapy, patients who received ribavirin had a mean transfusion number of 54 packed cell while those who received monotherapy had 33 packed cells as mean transfusion. The rate of hemoglobin decline to below $8 \mathrm{~g} / \mathrm{dL}$ was comparable between two groups (43 $\%$ in ribavirin $v s .37 \%$ in non-ribavirin group). The factors that influenced the number of transfusions were receiving ribavirin, duration of therapy (48 vs. 24 weeks and dropouts), history of splenectomy and inherent severity of thalassemia. Applying the generalized linear model of repeated measure showed that dynamics of hemoglobin during treatment in both treatment arms was not different significantly $(P=0.3)$ despite the higher transfusion rate in combination therapy group.

\subsection{Treatment Outcome in Children}

From 30 patients aged between 11 and 18 years, 22 patients received oral ribavirin. Mean ALT, serum HCV-RNA and serum ferritin was $100 \pm 10 \mathrm{IU} / \mathrm{L}, 650,000 \pm 120,000$ $\mathrm{IU} / \mathrm{mL}$, and $2383 \pm 330 \mathrm{ng} / \mathrm{mL}$ respectively. Furthermore, half of children had genotype 1 infection in both groups and their ALT, HCV-RNA and serum ferritin levels were also similar. In respect of liver histology, 18 out of 30 children had severe liver fibrosis (HAI $\geq 3$ ), and eight children had severe liver iron deposition (Pearl's score 4). Regarding virological response, 14 out of 22 (64\%) children that received oral ribavirin attained SVR, while SVR was observed in six out of eight $(75 \%)$ children who received monotherapy. Withdrawal causes were as follows: four children in ribavirin group were prematurely withdrawn due to non-response, two because of laboratory abnormalities, and one because of severe depression. Among subjects in peginterferon monotherapy, one subject

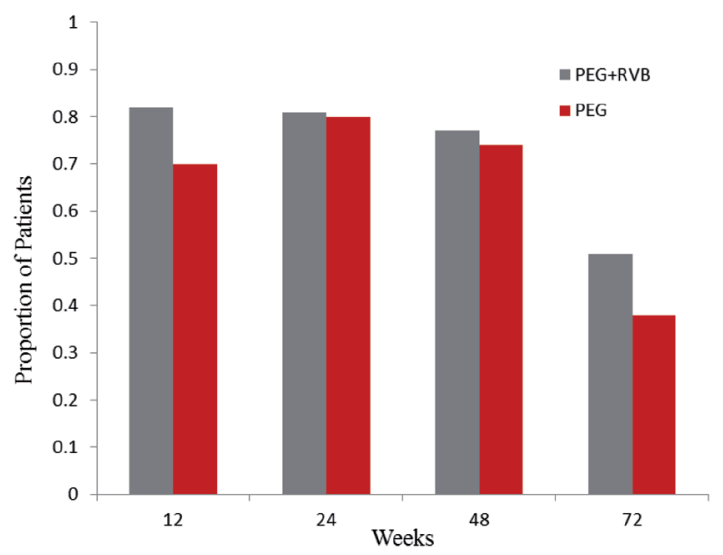

Figure 1. Virologic Response (HCV-RNA < 50 IU/Ml) Through Treatment and 24 Weeks Late 


$\begin{array}{ll}\text { Determinants } & \text { OR }(95 \% \mathrm{Cl}) \\ \text { Female vs. Male } & 2(1.12 ; 3.56) \\ \text { Age }<24 \text { vs. } \geq 24(\mathrm{y}) & 3.1(1.88 ; 5.11) \\ \text { RNA } \geq 600,000 \text { vs. }<600,000 & 0.65(0.39 ; 1.09) \\ \text { Elevated ALT vs. Normal } & 0.96(0.49 ; 1.87) \\ \text { HCV type non-1 vs. } 1 & 2(1.18 ; 3.39) \\ \text { Ferritin <2006 vs. } \geq 2006(\mathrm{ng} / \mathrm{ml}) & 1.33(0.78 ; 2.27) \\ \text { Fibrosis Score } \geq 3 \text { vs. }<3(\mathrm{HAl}) & 0.93(0.49 ; 1.77) \\ \text { Naïve vs. Prior treatment failure } & 1(0.58 ; 1.72) \\ \text { Combination vs. Monotherapy } & 2.2(1.24 ; 3.91)\end{array}$

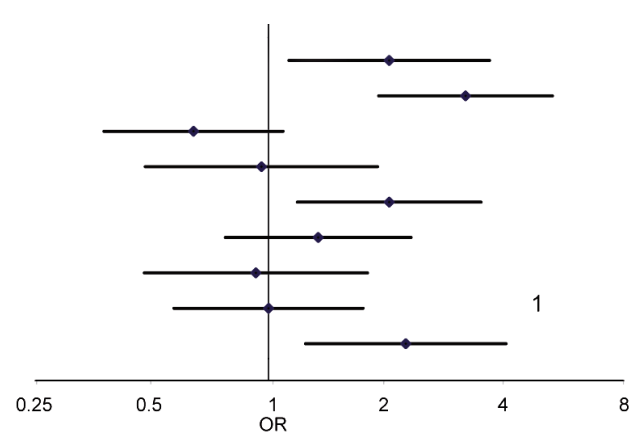

Figure 2. Results of Stepwise Multivariate Logistic Regression Including Baseline Characteristics to Predict a SVR in All Studied Population

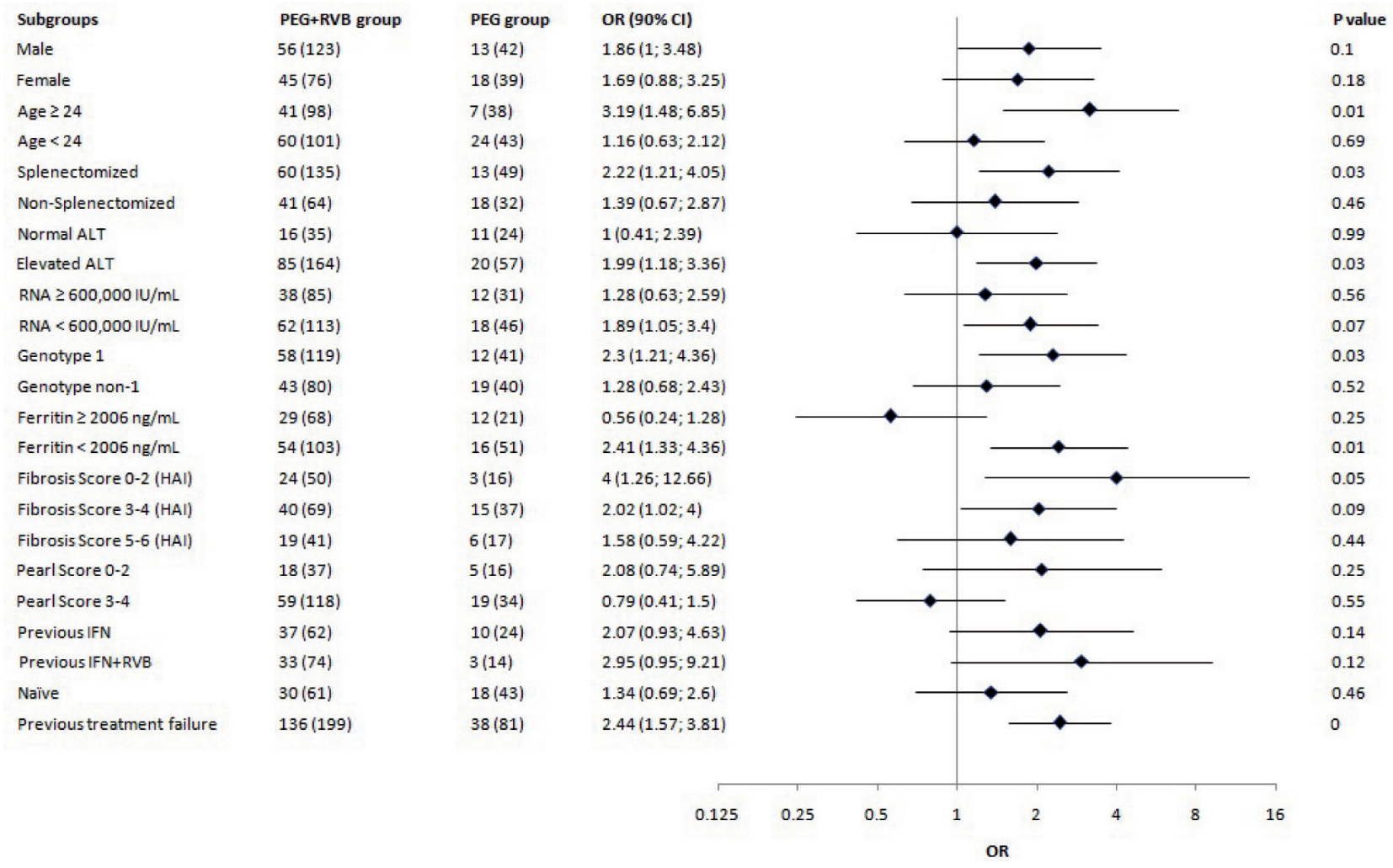

Figure 3. The Effect of Treatment Regimen on the Rate of SVR in Subgroups of Patients (The Chance of Type I Error Was Increased to 0.1 in Response to Low Statistical Power)

due to severe depression and one for familial reasons were withdrawn from the treatment. Twenty one (70 \%) children experienced at least one clinical adverse event, while the most prevalent adverse events were flue like syndrome (70\%), arthralgia (17\%), and myalgia (20\%).

\section{Discussion}

This large prospective study showed that low dose ribavirin in chronically HCV infected thalassemia patients is safe, tolerable and effective. Our primary efficacy analysis showed that SVR rate was significantly higher in group (A) patients who received combination therapy with low dose ribavirin in comparison with patients of group (B) who received monotherapy. Furthermore, multiple logistic-regression analysis with adjustment for baseline characteristics revealed that low dose ribavirin was even a stronger independent predictor of a SVR than what had been shown in our primary analysis. In addition to ribavi- 


\begin{tabular}{|c|c|c|}
\hline & Group A, No. (\%) & Group B, No. (\%) \\
\hline Death & $3(1.5)$ & $5(6)$ \\
\hline Non-response & $21(10)$ & $5(6)$ \\
\hline Dose Reduction & $39(19)$ & $15(18)$ \\
\hline $\begin{array}{l}\text { Neutropenia } \\
\text { Thrombocytopenia }\end{array}$ & $\begin{array}{l}33(16) \\
6(3)\end{array}$ & $\begin{array}{l}11(13) \\
4(5)\end{array}$ \\
\hline Headache & $46(23)$ & $20(25)$ \\
\hline Lethargy & $41(21)$ & $11(12)$ \\
\hline Dizziness & $23(12)$ & $8(10)$ \\
\hline Insomnia & $34(17)$ & $12(15)$ \\
\hline Irritability & $67(34)$ & $23(28)$ \\
\hline Depression & $15(7)$ & $10(12)$ \\
\hline Fatigue & $60(30)$ & $19(23)$ \\
\hline Weight loss & $12(6)$ & $3(3.7)$ \\
\hline Flue like syndrome & $11(5)$ & $5(6)$ \\
\hline Myalgia & $65(33)$ & $26(32)$ \\
\hline Arthralgia & $59(30)$ & $23(28)$ \\
\hline Nausea & $11(5)$ & $4(5)$ \\
\hline Diarrhea & $13(6)$ & $4(5)$ \\
\hline Cough & $19(9)$ & $9(11)$ \\
\hline Alopecia & $85(43)$ & $33(41)$ \\
\hline Dry skin & $26(13)$ & $21(26)$ \\
\hline Pruritus & $19(9)$ & $3(4)$ \\
\hline Rash & $5(2)$ & $3(4)$ \\
\hline Chills & $23(12)$ & $13(16)$ \\
\hline Fever & $48(24)$ & $23(28)$ \\
\hline
\end{tabular}

rin combination therapy, female gender, HCV type non-1 and age $<24$ years were predictors of SVR rate in the total studied population. These findings are consistent with the results of previous studies (28-30). Although in nonthalassemia patients, higher liver and serum iron content is determined to undermine virological response to anti-HCV therapy, no study except one case report has reported this among thalassemia patients (15, 16, 30-33). Serum ferritin and liver pearl score did not reach a significance level for predicting SVR among total studied population in the present investigation. Nonetheless, our subgroup analysis showed that patients with serum ferritin below $2006 \mathrm{ng} / \mathrm{mL}$ responded to ribavirin significantly higher than those with a lower level of serum ferritin. Analysis of liver pearl score did not display the same result. We believe that this is due to the fact that pearl score is not a sensitive measure of evaluating liver iron. According to our data, strict iron chelation to decrease serum and liver iron content before and during ribavirin therapy of thalassemia patients can strongly be advised. Other factors related to treatment such as necessity of peginterferon dose reduction, discontinuation of treat- ment and compliance with therapy was rather similar in both treatment arms. More patients discontinued the treatments owing to an insufficient therapeutic response in group (A) rather than group (B). The higher rate of previous treatment failure in group (A), even with ribavirin, could be a possible reason for this finding. On the other hand, the rate of treatment discontinuation because of safety concerns and death was almost the same among both studied groups. Furthermore, the heterogeneous patient population with regard to being treatment naive versus experienced, and the absence of randomization might make it difficult to assess the efficacy of ribavirin, especially considering the relatively small difference of SVR rates between RBV and non-RBV groups. However, our multivariate analysis showed that the effect of ribavirin became significantly higher when we adjusted the comparison according to other baseline characteristics including previous treatment $(\mathrm{OR}=\mathbf{2 . 2}$ after adjustment vs. 1.65 before adjustment). This finding displays a statistical advantage of RBV regardless of being treatment naive and experienced. As mentioned before, during treatment, 4 patients who had previous history of sple- 


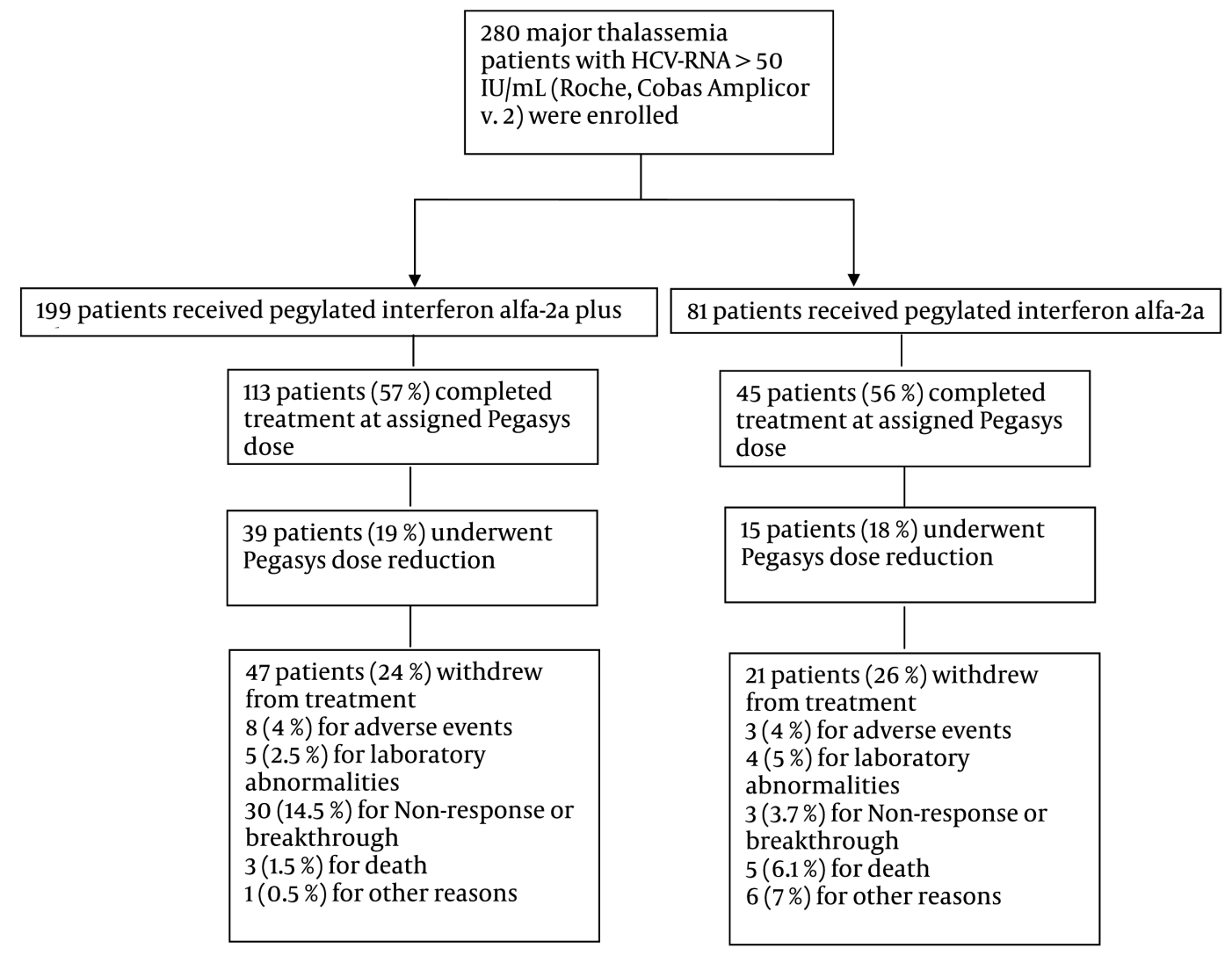

Figure 4. Enrollments and Follow-up of the Study Patients

nectomy died due to septicemia, two subjects died of diabetic ketoacidosis and two patients died because of heart failure. Indeed, our safety data suggest that thalassemia patients with significant concurrent life threatening comorbidities such as heart failure and insulin dependent diabetes mellitus, in addition to a history of splenectomy that makes the patients prone to certain infectious

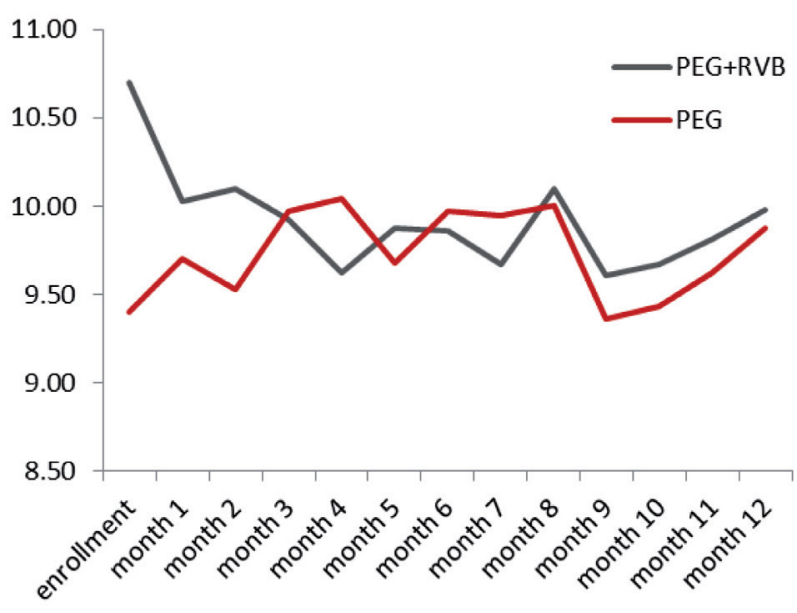

Figure 5. Pattern of Hemoglobin Change During Treatment in Both Treatment Arms agents, may not be good candidates for anti-HCV therapy. The decision on treatment and monitoring of thalassemia major patients should be well individualized according to other conditions that accompany patients' underlying hemoglobinopathy. Moreover, by close observation and frequent transfusion, the rate of severe hemoglobin drop can be minimized. According to the world medical association declaration of Helsinki regarding ethical principles for medical research involving human subjects, considering contraindication of ribavirin in thalassemia major patients, we did not carry out randomization or blindness. Nevertheless, the final decision on therapeutic regimen was made by patients, after being well informed about different aspects of possible efficacy of ribavirin and its probable side effects. As presented in Table 1 most of major predictors of virological response including HCV RNA level, sex, weight, BMI, HCV type, age and liver histological findings appeared to be similar in both groups (29,34-37). However, someone can argue that lack of randomization might underestimate the efficacy of peginterferon monotherapy or overestimate the safety of ribavirin. The reason is that patients with more severe thalassemia or more co-morbidity might have denied ribavirin treatment. This is unlikely in our opinion because comparison of baseline serum ferritin level shows that 
those who accepted ribavirin therapy had a significantly higher serum ferritin level and subsequently a more severe thalassemia than those who declined to receive ribavirin $(38,39)$. Moreover, our clinical records do not show that two groups of patients had a significant distinctive frequency of co-morbidities such as cardiovascular or endocrine diseases [29 (15\%) patients in monotherapy group and 19 (23\%) in combination therapy group]. In order to find out which groups of thalassemia patients derive the most benefits from ribavirin, a subgroup analysis was conducted. This analysis indicated that the major impact of low dose ribavirin was in thalassemia major patients with older than 24 years of age, a low serum ferritin $(<2006 \mathrm{ng} / \mathrm{mL})$, a previous treatment failure, an elevated ALT and liver fibrosis of 0-4 HAI, history of splenectomy and viral load $\leq 600,000 \mathrm{IU} / \mathrm{mL}$ and $\mathrm{HCV}$ genotype 1 . This later observation has been reported by others as well [20]. Our subgroup analysis may indicate that therapy with low dose ribavirin should be considered as the treatment of choice in certain subgroups of thalassemia major patients but not all patients. 30 thalassemia children with HCV infection participated in our study. The total rate of SVR was $66 \%$ among them and was significantly higher than adults' SVR rate (in aggregation $45 \%$ ). In contrast to adults, our data of 22 children who were treated with ribavirin showed that ribavirin did not further increase SVR rate of peginterferon monotherapy (64 vs. $75 \%$ of SVR) in patients less than 18 years of age. Furthermore, none of well-known factors that can influence virological response to anti-HCV treatment could predict the treatment outcome in children. In non-thalassemia children, genotype 2/3 infection had a higher rate of SVR than difficult to treat genotypes. However, we could not verify this finding in thalassemia major children $(40,41)$. In addition to virological outcome, our safety data revealed that peginterferon monotherapy or its combination therapy with ribavirin in children with thalassemia major is safe and well tolerated. According to the present study, adult thalassemia patients with HCV infection can be treated successfully with low dose ribavirin. Hence, we strongly advise combination therapy in thalassemia patients with aforementioned clinical characteristics. However, ribavirin does not seem to be beneficial in thalassemia patients below 18 years of age.

\section{Acknowledgements}

We are grateful to Professor Graham Foster, Queen Marys University of London, for constructive comments on the manuscript.

\section{Authors' Contribution}

Will be written by author

\section{Financial Disclosure}

None Declared.

\section{Funding Support}

This study was supported by a grant from Baqiyatallah Research Center for Gastroenterology and Liver Diseases (BRCGL), Iranian Blood Transfusion Organization Research Centre (IBTO), and Ministry of Health and Medical Education, Health Deputy.

\section{References}

1. Mirmomen S, Alavian SM, Hajarizadeh B, Kafaee J, Yektaparast B, Zahedi MJ, et al. Epidemiology of hepatitis B, hepatitis C, and human immunodeficiency virus infecions in patients with beta-thalassemia in Iran: a multicenter study. Arch Iran Med. 2006;9(4):319-23.

2. Berenguer J, Alvarez-Pellicer J, Martin PM, Lopez-Aldeguer J, VonWichmann MA, Quereda C, et al. Sustained virological response to interferon plus ribavirin reduces liver-related complications and mortality in patients coinfected with human immunodeficiency virus and hepatitis C virus. Hepatology. 2009;50(2):407-13.

3. Breitenstein S, Dimitroulis D, Petrowsky H, Puhan MA, Mullhaupt B, Clavien PA. Systematic review and meta-analysis of interferon after curative treatment of hepatocellular carcinoma in patients with viral hepatitis. BrJ Surg. 2009;96(9):975-81.

4. Poynard T, McHutchison J, Manns M, Trepo C, Lindsay K, Goodman Z, et al. Impact of pegylated interferon alfa-2b and ribavirin on liver fibrosis in patients with chronic hepatitis C. Gastroenterology. 2002;122(5):1303-13.

5. Singal AK, Singh A, Jaganmohan S, Guturu P, Mummadi R, Kuo YF, et al. Antiviral therapy reduces risk of hepatocellular carcinoma in patients with hepatitis C virus-related cirrhosis. Clin Gastroenterol Hepatol. 2010;8(2):192-9.

6. Bosques-Padilla F, Trejo-Estrada R, Campollo-Rivas O, Cortez-Hernandez C, Dehesa-Violante M, Maldonado-Garza H, et al. Peginterferon alfa-2a plus ribavirin for treating chronic hepatitis $\mathrm{C}$ virus infection: analysis of Mexican patients included in a multicenter international clinical trial. Ann Hepatol. 2003;2(3):135-9.

7. Ferenci P, Formann E, Laferl H, Gschwantler M, Hackl F, Brunner $\mathrm{H}$, et al. Randomized, double-blind, placebo-controlled study of peginterferon alfa-2a (40KD) plus ribavirin with or without amantadine in treatment-naive patients with chronic hepatitis C genotype 1 infection. J Hepatol. 2006;44(2):275-82.

8. Hadziyannis SJ, Sette H, Jr., Morgan TR, Balan V, Diago M, Marcellin $\mathrm{P}$, et al. Peginterferon-alpha2a and ribavirin combination therapy in chronic hepatitis $\mathrm{C}$ : a randomized study of treatment duration and ribavirin dose. Ann Intern Med. 2004;140(5):346-55.

9. Jacobson IM, Brown RS, Jr., Freilich B, Afdhal N, Kwo PY, Santoro J, et al. Peginterferon alfa-2b and weight-based or flat-dose ribavirin in chronic hepatitis $C$ patients: a randomized trial. Hepatol ogy. 2007;46(4):971-81.

10. Strader DB, Wright T, Thomas DL, Seeff LB. Diagnosis, management, and treatment of hepatitis C. Hepatology. 2004;39(4):114771.

11. Falasca K, Ucciferri C, Mancino P, Gorgoretti V, Pizzigallo E, Vecchiet J. Use of epoetin beta during combination therapy of infection with hepatitis c virus with ribavirin improves a sustained viral response. J Med Virol. 2010;82(1):49-56.

12. Sharvadze $L$, Tsertsvadze $T$, Gochitashvili N, Kakabadze $T$ Dolmazashvili E. Ifn/Rbv treatment induced anemia and its correction with epoetin alpha in patients with hepatitis C. Georgian Med News. 2006(137):62-5.

13. Ardalan FA, Osquei MR, Toosi MN, Irvanloo G. Synergic effect of chronic hepatitis $C$ infection and beta thalassemia major with marked hepatic iron overload on liver fibrosis: a retrospective cross-sectional study. BMC Gastroenterol. 2004;4:17.

14. Chen AC, Peng CT, Wu SF, Wu KH, Chiang IP, Tsai CH. Effect of deferiprone on liver iron overload and fibrosis in hepatitis-C-virusinfected thalassemia. Hemoglobin. 2006;30(2):209-14.

15. Franchini M, Targher G, Capra F, Montagnana M, Lippi G. The effect of iron depletion on chronic hepatitis $C$ virus infection. Hepatol Int. 2008;2(3):335-40. 
16. Fujita N, Sugimoto R, Urawa N, Araki J, Mifuji R, Yamamoto M, et al. Hepatic iron accumulation is associated with disease progression and resistance to interferon/ribavirin combination therapy in chronic hepatitis C. J Gastroenterol Hepatol. 2007;22(11):1886-93.

17. Isom HC, McDevitt EI, Moon MS. Elevated hepatic iron: a confounding factor in chronic hepatitis C. Biochim Biophys Acta. 2009;1790(7):650-62.

18. Lin TJ, Liao LY, Lin SY, Lin CL, Chang TA. Influence of iron on the severity of hepatic fibrosis in patients with chronic hepatitis $\mathrm{C}$. World J Gastroenterol. 2006;12(30):4897-901.

19. Soe K, Hishikawa Y, Fukuzawa Y, Win N, Yin KS, Win KM, et al. Possible correlation between iron deposition and enhanced proliferating activity in hepatitis $\mathrm{C}$ virus-positive hepatocellular carcinoma in Myanmar (Burma). J Gastroenterol. 2007;42(3):225-35.

20. Alavian SM, Tabatabaei SV. Treatment of chronic hepatitis C in polytransfused thalassaemic patients: a meta-analysis. J Viral Hepat. 2010;17(4):236-44.

21. Harmatz P, Jonas MM, Kwiatkowski JL, Wright EC, Fischer R, Vichinsky E, et al. Safety and efficacy of pegylated interferon alpha$2 a$ and ribavirin for the treatment of hepatitis $C$ in patients with thalassemia. Haematologica. 2008;93(8):1247-51.

22. Inati A, Sharara A, Ghorra S, Aoun E, Taha M, Koussa S, et al. Study on hepatitis $\mathrm{C}$ treatment using ribavirin and pegylated interferon in thalassemia patients (SCRIPT): One year report. Blood. 2004;104(11):28B-9B.

23. Inati A, Taher A, Ghorra S, Koussa S, Taha M, Aoun E, et al. Efficacy and tolerability of peginterferon alpha-2a with or without ribavirin in thalassaemia major patients with chronic hepatitis $C$ virus infection. BrJ Haematol. 2005;130(4):644-6.

24. Li CK, Chan PK, Ling SC, Ha SY. Interferon and ribavirin as frontline treatment for chronic hepatitis $\mathrm{C}$ infection in thalassaemia major. BrJ Haematol. 2002;117(3):755-8.

25. Sherker AH, Senosier M, Kermack D. Treatment of transfusion-dependent thalassemic patients infected with hepatitis $\mathrm{C}$ virus with interferon alpha-2b and ribavirin. Hepatology. 2003;37(1):223.

26. Telfer PT, Garson JA, Whitby K, Grant PR, Yardumian A, Hoffbrand $\mathrm{AV}$, et al. Combination therapy with interferon alpha and ribavirin for chronic hepatitis $C$ virus infection in thalassaemic patients. BrJ Haematol. 1997;98(4):850-5.

27. Alavian SM, Miri SM, Keshvari M, Elizee PK, Behnava B, Tabatabaei SV, et al. Distribution of hepatitis C virus genotype in Iranian multiply transfused patients with thalassemia. Transfusion. 2009;49(10):2195-9.

28. Alavian SM, Tabatabaei SV, Keshvari M, Behnava B, Miri SM, Karim Elizee P, et al. Peginterferon alpha-2a and ribavirin treatment of patients with haemophilia and hepatitis $C$ virus infection: a single-centre study of 367 cases. Liver Int. 2010;30(8):1173-80.

29. Hsu CS, Liu CH, Liu CJ, Chen CL, Lai MY, Chen PJ, et al. Factors af- fecting early viral load decline of Asian chronic hepatitis $C$ patients receiving pegylated interferon plus ribavirin therapy. Antivir Ther. 2009;14(1):45-54.

30. Ladero JM, Lopez-Alonso G, Devesa MJ, Cuenca F, Ortega L, Agreda $\mathrm{M}$, et al. Oscillations in serum ferritin associated with antiviral therapy in chronic hepatitis C. Rev Esp Enferm Dig. 2009;101(1):3140.

31. Alavian SM, Tabatabaei SV. Therapy of hepatitis $\mathrm{C}$ in thalassemia: the influence of iron on achieving sustained viral response. Ann Hematol. 2010;89(2):215-6.

32. Fujita N, Horiike S, Sugimoto R, Tanaka H, Iwasa M, Kobayashi $\mathrm{Y}$, et al. Hepatic oxidative DNA damage correlates with iron overload in chronic hepatitis C patients. Free Radic Biol Med. 2007;42(3):353-62.

33. Taher AT, Musallam KM, Khalife M, Barada K. Hepatitis C antiviral response in thalassemia: what is the role of liver iron concentration? Ann Hematol. 2009;88(10):1033-4.

34. Al Ashgar H, Helmy A, Khan MQ, Al Kahtani K, Al Quaiz M, Rezeig $\mathrm{M}$, et al. Predictors of sustained virological response to a 48 week course of pegylated interferon alfa-2a and ribavirin in patients infected with hepatitis C virus genotype 4. Ann Saudi Med. 2009;29(1):4-14.

35. Kaserer K, Fiedler R, Steindl P, Muller CH, Wrba F, Ferenci P. Liver biopsy is a useful predictor of response to interferon therapy in chronic hepatitis C. Histopathology. 1998;32(5):454-61.

36. Kryczka W, Zarebska-Michaluk D, Chrapek M. Assessment of selected clinical factors as predictors of response to combined interferon-alpha plus ribavirin therapy among patients with chronic hepatitis C. Med Sci Monit. 2003;9(Suppl 3):32-5.

37. Testino G, Sumberaz A, Ancarani AO, Borro P, Ravetti G, Ansaldi $\mathrm{F}$, et al. Influence of body mass index, cholesterol, triglycerides and steatosis on pegylated interferon alfa-2a and ribavirin treatment for recurrent hepatitis $\mathrm{C}$ in patients transplanted for HCV and alcoholic cirrhosis. Hepatogastro. 2009;56(90):501-3.

38. Farmaki K, Tzoumari I, Pappa C, Chouliaras G, Berdoukas V. Normalisation of total body iron load with very intensive combined chelation reverses cardiac and endocrine complications of thalassaemia major. Br J Haematol. 2010;148(3):466-75.

39. Lekawanvijit $\mathrm{S}$, Chattipakorn N. Iron overload thalassemic cardiomyopathy: iron status assessment and mechanisms of mechanical and electrical disturbance due to iron toxicity. Can J Cardiol. 2009;25(4):213-8.

40. Hu J, Doucette K, Hartling L, Tjosvold L, Robinson J. Treatment of hepatitis $\mathrm{C}$ in children: a systematic review. PLoS One. 2010;5(7):e11542.

41. Sokal EM, Bourgois A, Stephenne X, Silveira T, Porta G, Gardovska D, et al. Peginterferon alfa-2a plus ribavirin for chronic hepatitis $\mathrm{C}$ virus infection in children and adolescents. J Hepatol. 2010;52(6):827-31 